\title{
INFLUENCE OF RELATIVE HUMIDITY AND TEMPERATURE ON CULTIVATION OF Pleurotus SPECIES
}

\author{
Hamed Aghajani', Ehsan Bari',, Mohsen Bahmani', Miha Humar', \\ Mohammad Ali Tajick Ghanbary, Darrel D. Nicholas', Emran Zahedian²
}

\begin{abstract}
Fungi exhibit different behavior under different conditions and react to light, temperature, moisture content etc. The objective of this study was to evaluate the degradation capability of three common white rot fungi, namely: Pleurotus ostreatus, Pleurotus pulmonarius, and Lentinus sajor-caju. The respective fungi were cultivated on rice straw under three different environmental conditions for 90 days. The fungi were collected, pure cultured, DNA extracted, and sequenced by ITS regions. The highest consumption of substrate occurred under the Cellar (dark) exposure condition with Pleurotus pulmonarius producing the least mass loss. The least amount of degradation occurred under the Air (daylight) condition for all of the fungi with the exception of Pleurotus pulmonarius. Exposure to light promoted the formation of fruiting bodies.
\end{abstract}

Keywords: Lentinus sajor-caju, mushroom cultivation, Pleurotus ostreatus, Pleurotus pulmonarius, wood fungi.

\section{INTRODUCTION}

Fungi exhibit different behavior under different environmental conditions such as moisture content, temperature, light, levels of oxygen and nitrogen, and $\mathrm{pH}$, for a given substrate (Messner et al. 2003, Schwarze et al. 2004, Nikolouli et al. 2016). Many wood decay fungi are mesophilic and are able to grow at temperature ranges between $20-30{ }^{\circ} \mathrm{C}$ (Schmidt 2006). Some wood inhabiting fungi have the capability of colonizing wood at temperature levels around $50{ }^{\circ} \mathrm{C}$ (Eaton and Hale 1993). Fruiting bodies of some fungi respond to light due to their phototropic behavior. Many wood decaying fungi, Hymenomycetes, react to light by producing sporocarps (Schmidt 2006, Eaton and Hale 1993). Fungi may also respond to the direction from which the light is orientated (Jennings and Lysek 1999). The stipe grows towards the light source during the primordium growth of Basidiomycetes. Fungi of the genus Pleurotus have an important place among the commercially employed basidiomycetes because they have gastronomic, nutritional, biotechnological and medicinal properties and can be easily cultivated on a variety of substrates. In addition to studies on solid cultures focusing on the production of fruiting bodies, the submerged cultivation of the genus Pleurotus has also been studied by several authors with varied objectives including the production of: liquid inoculum (Rosado et al. 2002), extracellular enzymes (Garzillo et al. 1994), flavoring agents (Martin 1992), ß-glucosidases (Morais et al. 2002),

${ }^{1}$ Department of Forestry, Sari Agriculture Science and Natural Resources University, Sari, Iran.

${ }^{2}$ Department of Wood Science and Engineering, Technical Faculty of No. 2, Mazandaran Branch, Technical and Vocational University (TVU), Sari, Iran.

${ }^{3}$ Department of Natural Resources and Earth Science, Shahrekord University, Shahrekord, Iran.

${ }^{4}$ Department of Wood Science and Technology, Biotechnical Faculty, University of Ljubljana, Ljubljana, Slovenia.

${ }^{5}$ Department of Mycology and Plant Pathology. College of Agronomic Sciences, Agriculture and Natural Resources University, Sari, Iran.

${ }^{6}$ Department of Sustainable Bioproducts, Mississippi State University, Mississippi State. USA.

"Corresponding author: bari lenzites@yahoo.com

Received: 04.10.2017 Accepted: 02.05.2018 
antimicrobials (Beltran et al. 1997, Benkortbi et al. 2007) and vitamins (Solomko and Eliseeva 1998). However, solid state cultivation is still the main method of Pleurotus cultivation. The worldwide production of edible mushrooms cultivated on straw and wood is in the range of 2 million tons (fresh weight basis) per year. Thus, cultivation of mushrooms represents one of the economically most important microbial conversions of lignocelluloses (Chang and Hayes 1978). The Oyster mushroom, Pleurotus ostreatus, grows well on several substrates, including lignocellulosic residues (Pettipher 1978). In North America and Europe (predominately in Italy and Hungary), Pleurotus species such as Pleurotus ostreatus are grown on chopped wheat straw. Also, chopped lignocellulosics originating from agricultural residues and forestry residues are used by hobby breeders as well as commercially. Several Pleurotus species used for cultivation but nine species of the Pleurotus family are distributed in the forests of Iran (Ershad 2009). These species grow on Fagus orientalis, Quescus spp., Populus spp., Ulmus spp., and Salix alba and act in both saprophytes and wound parasites phases (Aghajani et al. 2017). Three species of Pleurotus: Pleurotus ostreatus, L. sajor-caju, and Pleurotus pulmonarius are of particular interest, as they can grow on a variety of woods, such as beech, oak, hornbeam, poplar, and alder. On the other hand, the ecology of these respective fungal species varies considerably. Hence, the aim of this study was to determine the effects of temperature, relative humidity, and light on the rate of fungal growth for these fungi. The performance criteria used in evaluating these fungi were the yield of fruiting bodies and their ability to degrade wood. These data are important from the fungal cultivation point of view as well as for assessment of the optimal conditions for fungal degradation. These data can serve as an input data for modeling of the service life of lingo-cellulosic materials in various climate regions.

\section{MATERIALS AND METHODS}

\section{Fungal collection, isolation, and identification}

The fruiting bodies of three fungi, Pleurotus ostreatus (MG835874), Pleurotus pulmonarius (MG835875), and Lentinus sajor-caju (MG835876) were collected from fallen beech and oak trees in Alamdardeh forest (located in Sari $\left(36^{\circ} 22^{\prime} 34^{\prime \prime} \mathrm{N}, 53^{\circ} 14^{\prime} 59^{\prime \prime} \mathrm{E}\right)$, stored in a cold chamber $\left(-10^{\circ} \mathrm{C}\right)$ and immediately transported to the laboratory. About $20 \mathrm{mg}$ of the mushroom tissue was taken from the internal part of the cap of each fungus, placed on potato dextrose agar (PDA) and incubated at $25^{\circ} \mathrm{C}$ for 3 days. After sufficient fungal hyphae development, the single tip of several hyphae were isolated and transferred onto new malt extract agar (MEA) and incubated at $25^{\circ} \mathrm{C}$ for 5 days. Thereafter, subcultures of all three fungi was transferred to $4 \%$ MEA and kept at $4^{\circ} \mathrm{C}$ until used.

Molecular identification of the fungi was performed in accordance with methods described by Bari (2014) and Bari et al. (2017). Mycelium was washed with sterile distilled water. Dehydrated, the Mycelium was reduced to powder in a sterile mortar with nitrogen. About $10 \mathrm{mg}$ of the powdered mycelium was placed in a vial (Eppendorf tube). $600-\mu \mathrm{l}$ of CTAB solution and $1-\mu \mathrm{l} \beta$-Mercapto-ethanol $(2 \%)$ were added to the vial, and transferred to a hot water chamber (Ben-Murry) $65^{\circ} \mathrm{C}$ for $45 \mathrm{~min}$, and then the vials were inverted for $15 \mathrm{~min}$. Next, $600-\mu \mathrm{l}$ of chloroform: isoamylalcohol (24:1) was added to the vials prior to centrifuging at $12000 \mathrm{rpm}$ for $10 \mathrm{~min}$. Thereafter, $500-\mu \mathrm{l}$ of supernatants containing DNA were transferred to new vials and about the same volume of cold isopropanol $\left(-20^{\circ} \mathrm{C}\right)$ was added. The vials were kept in the freezer at $-20^{\circ} \mathrm{C}$ for $30 \mathrm{~min}$. Afterward the vials were centrifuged at 13000 $\mathrm{rpm}$ for $15 \mathrm{~min}$, the liquid phase was removed and the vials were washed with $1 \mathrm{ml}$ of $70 \%$ ethanol for $1 \mathrm{~min}$. After removing the ethanol, $70-\mu \mathrm{l}$ of sterile distilled water was added and the vials were refrigerated for $30 \mathrm{~min}$ before storing in a freezer at $-20^{\circ} \mathrm{C}$.

For the polymerase chain reaction (PCR), ITS4 and ITS5 primers were chosen. Two replicates were used. The PCR protocol was as follows: an initial denaturization of $4 \mathrm{~min}$ at $98^{\circ} \mathrm{C}$, then 35 cycles of $30 \mathrm{sec}$ at $94^{\circ} \mathrm{C}$ for denaturization, $30 \mathrm{sec}$ at $58^{\circ} \mathrm{C}$ for annealing, $1 \mathrm{~min}$ at $72^{\circ} \mathrm{C}$ for extension, and a final extension of $7 \mathrm{~min}$ at $72^{\circ} \mathrm{C}$. Aliquots of PCR products were examined on $2 \%$ agarose gel. Gels were stained with GelStar Nucleic Acid Gel Stain (Lonza Rockland, Inc, USA) and examined using UV light. PCR products were sequenced at Takapozist Co. (Bioneer- Korea). Sequence identification 
was done by comparison with sequences deposited in the DNA databases using the BLAST program Schmidt et al. (2012).

\section{Sample preparation and incubation}

The rice straw was cut into $20-25 \mathrm{~cm}$ long pieces and then washed in hot water at $100^{\circ} \mathrm{C}$ for 15 min. before oven drying at $103 \pm 2^{\circ} \mathrm{C}$ for $24 \mathrm{~h}$. Afterward, about $50 \mathrm{~g}$ of rice straw was placed in a plastic bag (common nylon) and autoclaved $\left(1,5\right.$ bar) at $121^{\circ} \mathrm{C}$ for $20 \mathrm{~min}$. The rice straw had an average moisture content of about $25 \%$. The bags were then inoculated with the purified fungal mycelia. Three environment conditions were selected for incubation (Table 1).

Table 1. Environmental conditions for the three exposure conditions used during incubation of the samples.

\begin{tabular}{lccc}
\hline Type of Exposure & Cellar & Room & Air \\
\hline Lighting & Dark & lamp (200 watt) & Daylight \\
Relative Humidity $(\%)$ & $80-85$ & $75-85$ & $65-75$ \\
Temperature Range $\left({ }^{\circ} \mathrm{C}\right)$ & $29-31$ & $19-21$ & $26-28$ \\
\hline
\end{tabular}

Selected micro-climate conditions were chosen, as they represent the most typical conditions where cultivation of the fungi could take place, or potential building infestation could appear. Three replicates were used for each fungus as well as for the environment conditions. The samples were incubated for 90 days. Mass loss was determined and was calculated in accordance with the following formula Equation 1:

$$
\operatorname{ML}(\%)=\frac{M_{i}-M_{d}}{M_{i}} \times 100
$$

Where $\mathrm{ML}$ is mass loss $(\%) ; \mathrm{M}_{\mathrm{i}}$ : dry mass before decay $(\mathrm{g}) ; \mathrm{M}_{\mathrm{d}}$ : dry mass after decay $(\mathrm{g})$.

\section{Chemical analysis}

Cell wall components of the straw were determined by TPPI methods. Lignin and cellulose determination was carried out using T-222 om-98 (TAPPI 1998) and T 17 wd-70 (TAPPI 1997) procedures, respectively.

For Klason lignin determination one g of straw powder (free from extractives) was mixed with $72 \%$ sulfuric acid $(15 \mathrm{ml})$ for $2 \mathrm{~h}$ at room temperature. The mixture was then diluted with $560 \mathrm{ml}$ of boiling distilled water to obtain a 3\% solution in sulfuric acid, which was heated under reflux for $4 \mathrm{~h}$ and then filtered. The Klason lignin residue was washed with hot distilled water and dried at $103^{\circ} \mathrm{C}$ to constant weight. The Klason lignin content was calculated in accordance with the following formula Equation 2:

$$
K L(\%)=\frac{S d-K L}{S d} \times 100
$$

where: Sd is the dried weight of sawdust and KL is the dried weight of Extracted Klason lignin.

Cellulose content was determined by mixing $2 \mathrm{~g}$ of extractive free sawdust with $96 \%$ EtOH (100 $\mathrm{ml}$ ) and then diluted with $65 \%$ nitric acid to $50 \mathrm{ml}$. The mixture was heated under reflux for $1 \mathrm{~h}$ and filtered. The cellulose residue was then washed with warm distilled water, dried at $103^{\circ} \mathrm{C}$ to constant weight. Cellulose content was calculated in accordance with the following formula Equation 3: 


$$
\text { Cellulose }(\%)=\frac{S d-E C}{S d} \times 100
$$

where: Sd is the dried weight of sawdust and EC is the dried weight of extracted cellulose

\section{Statistical analysis}

A Student t-test for each exposure period (95\% level of confidence) was used to compare the mass loss and chemical components of decayed and non-decayed specimens. A Two-way ANOVA was conducted to examine the effect of decay condition on mass and chemical losses. All statistical analyses were performed using SPSS version 17 (2010).

\section{RESULTS AND DISCUSSION}

\section{Mass loss determination}

Figure 1 shows the mass loss of rice straw caused by the fungi after 90 days incubation. The rice straw was white to colorless after incubation and had a light and almost stringy consistency. The fungus appears to degrade the majority of the lignin, which resulted in the bleaching and whitening due to the abundance of the cellulose. This presumption is connected based on the fact that Pleurotus is a white rot decay fungus (Eaton and Hale 1993, Martinez et al. 2001). Several white-rot fungi can cause selective rot in most wood species (Camarero et al. 1994, Martínez et al. 2005). However, non-selective white rot is also reported and in general Pleurotus causes simultaneous type of white rot (Bari et al. 2015a). The highest mass losses were observed for Pleurotus ostreatus and L. sajor-caju incubated straw under Cellar conditions (Figure 1).

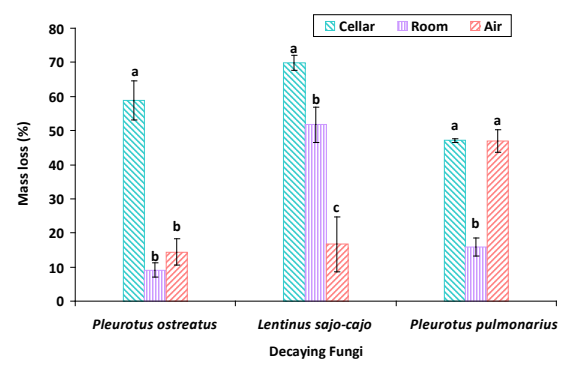

Figure 1. Mass losses of rice straw exposed to white rot fungi under different environmental conditions after 90 days incubation.

It is also apparent that the mass loss caused by Pleurotus pulmonarius was comparable for straw incubated under both Air and Cellar conditions. On the other hand, mass loss of rice straw after exposure to Pleurotus ostreatus in the air and Room conditions was negligible compared to other fungi. For example, rice straw exposed to Pleurotus pulmonarius in air was $46,88 \%$ while mass losses for straw exposed to Pleurotus ostreatus under the same conditions was (14,40\%) (Figure 1). The lowest mass losses of rice straw were obtained after exposure to L. sajor-caju, and Pleurotus pulmonarius incubated in Air and Room conditions, respectively. Temperature appeared to play an important role in the degradation ability of L. sajor-caju and Pleurotus ostreatus in contrast to Pleurotus pulmonarius. The influence of temperature and relative humidity on fungal activity is well known (Cartwright and Findlay 1934, Viitanen 1997).

\section{Changes in the chemical composition of rice straw after incubation}

An overview of the chemical changes in rice straw due to the fungal degradation under the three environmental conditions is shown in Figure 2. The fungi caused considerable chemical degradation which was influenced by the environmental conditions (Figure 2). 


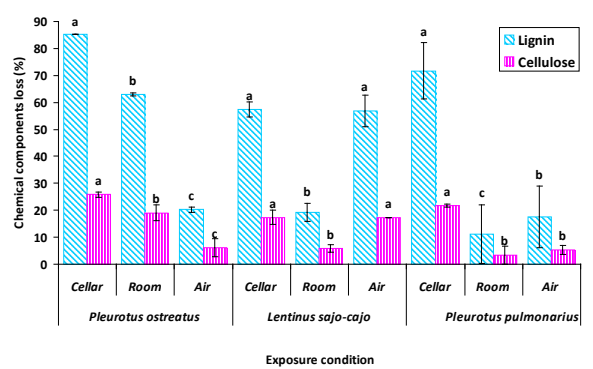

Figure 2. Chemical component losses of rice straw after exposure to white rot fungi under different environmental conditions after 90 days incubation.

Degradation of both lignin and cellulose was greatest for Pleurotus ostreatus under all three environmental conditions with the degradation being greatest under the Cellar and Room conditions. Overall, the consumption of polymeric components of the cell wall of rice straw after exposure to Pleurotus pulmonarius and L. sajor-caju was lower in comparison to that of Pleurotus ostreatus. Moreover, lignin was heavily degraded by the fungi during incubation. The Cellar incubation condition appears to have the greatest effect on lignin degradation caused by Pleurotus ostreatus. During the cellar incubation, lignin consumption was 71,73 and $57,41 \%$ by Pleurotus pulmonarius and L. sajorcaju fungi, respectively, while it was $85,19 \%$ for Pleurotus ostreatus. The highest amount of lignin degradation for rice straw was observed under Air and Room incubation. Our data clearly confirmed previous report showing that the Pleurotus species readily degrade lignin (Martinez et al. 2001). Cellulose was less degraded than lignin for all of the three fungi investigated, indicating that these fungi preferentially degraded lignin under the conditions investigated. The lowest cellulose degradation was obtained for straw exposed to Pleurotus pulmonarius and L. sajor-caju under Air conditions. Severe reduction in the rice straw cellulose content due to the Pleurotus pulmonarius degradation was observed by Adaskaveg et al. (1995). It showed that temperature was one of the most important factors influenced fungal behavior. These authors stated that when the temperature changed from 40 to 45 ${ }^{\circ} \mathrm{C}$, some wood decay fungi such as Ganoderma species switched from the selective to simultaneous rot. However, in another it was shown that the white rot fungus Pleurotus ostreatus switched from simultaneous rot to selective degradation when the wood moisture content decreased from 65 to $45 \%$ (Bari et al. 2015a, Bari et al. 2015b, Bari et al. 2016; Bari et al. 2018). On one hand, Messner et al. (2003) indicated that moisture content was important for was appeared to expression of fungal enzymes and subsequent degradation of lignin bonds in wood cell walls. On the other hand, fungi use a hydrolysis system for degradation of cellulose bonds (Kubicek 2013).

\section{Yield of fungal fruit-bodies}

One of the key objectives of this research was to elucidate the influence of the growth conditions on the yield of the fruiting bodies by Pleurotus fungi. Production of fruiting bodies for the three Pleurotus fungi grown on rice straw are shown in Figure 3. Results indicated that L. sajor-caju (Figure $3 \mathrm{E} \& \mathrm{~F}$ ) produced abundant fruiting bodies more rapidly compared to the Pleurotus ostreatus (Figure $3 \mathrm{C} \& \mathrm{D}$ ) and Pleurotus pulmonarius (Figure $3 \mathrm{A \& B}$ ), respectively. The Pleurotus osteratus samples were degraded due to the sensitivity to humid conditions. On the other hand, L. sajor-caju produced more fruiting bodies under the Air incubation in comparison to the Room and Cellar conditions. Pleurotus pulmonarius also produced fruiting bodies under Air and Room incubation while Pleurotus ostreatus was not able to produce fruiting bodies under any of the incubation conditions tested. Light has been shown to affect formation of fungi fruiting bodies (Butin 1956). Light is the signal indicating that the mycelium has reached the surface, where the spores can be produced in an environment suitable for spore release (Jennings and Lysek 1999). Short wavelengths (blue light) stimulate fruiting bodies while longer wavelengths are ineffective. The light acceptor for the photons hitting the mycelium is riboflavin, which then reduces a cytochrome. The required light quantities are low, below those of the full moonlight in a clear sky (Schmidt 2006). Moisture content of the substrate is an important factor in the growth and metabolic activity of fungi (Schmidt 2006, Stienen et al. 2014). White rot fungi attack the cell wall of plants by a hydrolysis and hydrogen peroxide production is important in the degradation 
of lignin bonds (Eriksson et al. 1990). The optimum moisture content of the substrate for the growth of Pleurotus mushroom is between 50\% and 80\% (Mohammadi Goltapeh and Pourjam 2010).

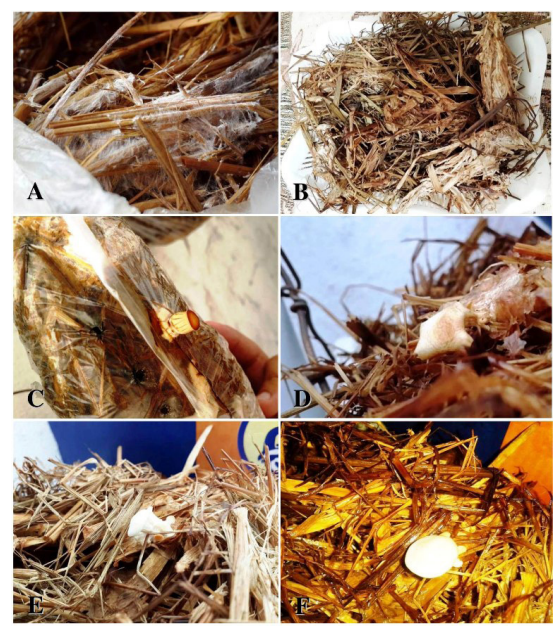

Figure 3. Fungal growing and production of fruit body on the rice straw after 90 days incubation in (A\&B) Pleurotus pulmonarius, (C\&D) Pleurotus oatreatus, and (E\&F) L. sajur-cajo in air incubation.

\section{CONCLUSIONS}

The highest consumption of substrate occurred under Cellar conditions, where the fungi were incubated in the dark under high humidity and temperature conditions. Pleurotus pulmonarius produced the lowest degradation of rice straw. The lowest amount of degradation for all fungi was observed for samples exposed in the air (daylight) condition. The highest yield was obtained in the samples exposed to L. sajor-caju. Moreover, light was found to be the most important variable affecting formation of fruiting bodies.

\section{ACKNOWLEDGMENTS}

Thanks to Mrs. Hakimeh Ziaie Juibari, Sari Agriculture Science and Natural Resources University for collaboration in preparation samples of fungal for DNA extraction.

\section{REFERENCES}

Adaskaveg, J.E.; Gilbertson, R.L.; Dunlap, M.R. 1995. Effects of incubation time and temperature on in vitro selective delignification of silver leaf Oak by Ganoderma colossum. Applied and Environmental Microbiology 61(1): 138-144.

Aghajani, H.; Marvei Mohadjer, M.R.; Bari, E.; Ohno, K.; Shirvany, A.; Asef, M.R. 2017. Assessing the biodiversity of wood decay fungi in Northern forests of Iran. Proceedings of the National Academy of Sciences, India Section B: Biological Sciences 87(4):1-7.

Bari, E. 2014. Potential of biological degradation of oriental beech wood by the white-rot fungus Pleurotus ostreatus and the effects on mechanical and chemical properties there of and its comparison with standard the white-rot fungus Trametes versicolor. Ms.c thesis, Sari Agriculture and Natural Resources University, Sari, Iran.

Bari, E.; Nazarnezhad, N.; Kazemi, S.M.; Tajick Ghanbary, M.A.; Mohebby, B.; Schmidt, 
O.; Clausen, C.A. 2015a. Comparison of degradation capabilities of the white rot fungi Pleurotus ostreatus and Trametes versicolor. International Biodeterioration \& Biodegradation 104: 231-237.

Bari, E.; Oladi, R.; Schmidt, O.; Clausen, C.A.; Ohno, K.; Nicholas, D.D.; Ghodskhah Daryaei, M.; Karim, M. 2015b. Influence of xylem ray integrity and degree of polymerization on bending strength of beech wood decayed by Pleurotus ostreatus and Trametes versicolor. International Biodeterioration \& Biodegradation 104: 299-306.

Bari, E; Taghiyari, H.R.; Naji, H.R; Schmidt, O.; Ohno, M.K.; Clausen, C.A.; Bakar, E.S. 2016. Assessing the destructive behavior of two white-rot fungi on beech wood. International Biodeterioration \& Biodegradation 114: 129-140.

Bari, E.; Karim, M.; Oladi, R.; Tajick Ghanbary, M.A.; Ghodskhah Daryaei, M.; Schmidt, O.; Benz, J.P.; Emaminasab, M. 2017. A comparison between decay patterns of the white-rot fungus Pleurotus ostreatus in chestnut-leaved oak (Quercus castaneifolia) shows predominantly simultaneous attack both in vivo and in vitro. Forest Pathology 47:e12338.

Bari, E.; Mohebby, B.; Naji, H.R.; Oladi, R.; Yilgor, N.; Nazarnezhad, N.; Ohno, K.; Nicholas, D.D. 2018. Monitoring the cell wall characteristics of degraded beech wood by white-rot fungi: anatomical, chemical, and photochemical study. Maderas-Cienc Tecnol 20(1): 35-56.

Beltran, G.M.J.; Estarron, E.M.; Ogura, T. 1997. Volatile compounds secreted by the oyster mushroom (Pleurotus ostreatus) and their antibacterial activity. Journal of Agricultural and Food Chemistry 45 (10): 4049-4052.

Benkortbi, O.; Hanini, S.; Bentahar, F. 2007. Batch kinetics and modeling of Pleuromutilin production by Pleurotus mutilis. Biochemical Engineering Journal 36(1): 14-18.

Butin, H. 1956. Untersuchungen über Resistenz und Krankheitsanfälligkeit der Pappel gegenüber Dothichiza populea Sacc. et Br. Phytopathologische Zeitschrift 28 (4): 353-374

Camarero, S.; Galletti, G.C.; Martínez, A.T. 1994. Preferential degradation of phenolic lignin units by two white rot fungi. Applied and environmental microbiology 60: 4509-4516.

Cartwright, K.S.G.; Findlay, W.P.K. 1934. Studies in the physiology of wood-destroying fungi. Annals of Botany 48: 481-495.

Chang, S.T.; Hayes, W.A. 1978. The Biology and Cultivation of Edible Mushrooms. Academic Press Inc.: New York.

Eaton, R.A.; Hale, M.D.C. 1993. Wood: decay, pests and protection. Chapman and Hall Ltd.: London.

Eriksson, K.E.L.; Blanchette, R.A.; Ander, Pleurotus 1990. Microbial and enzymatic degradation of wood and wood components. Springer Science \& Business Media: Berlin.

Ershad, D. 2009. Fungi of Iran. Ministry of jihad-e-agriculture. Agricultural research, education and extension organization, Tehran, p 535

Garzillo, A.M.V.; Di Paolo, S.; Ruzzi, M.; Buonocore, V. 1994. Hydrolytic properties of extracellular cellulases from Pleurotus ostreatus. Applied Microbiology and Biotechnology 42: 476481.

Jennings, D.H.; Lysek, G. 1999. Fungal biology, $2^{\text {nd }}$ ed. Bios:Oxford.

Kubicek, C. Pleurotus 2013. Fungi and lignocellulosic biomass. Chichester: John Wiley \& Sons, Inc: Chichester. 
Martin, A.M. 1992. Study of the growth and biomass composition of the edible mushroom Pleurotus ostreatus. Developments in Food Science Human Nutr 239-248.

Martinez, A.T.; Camarero, S.; Gutiérrez, A.; Bochini, P.; Galleti, G.C. 2001. Studies on wheat lignin degradation by Pleurotus species using analytical pyrolysis. Journal of Analytical and Applied Pyrolysis 58: 401-411.

Martínez, A.T.; Speranza, M.; Ruiz-Dueñas, F.J.; Ferreira, P.; Camarero, S.; Guillén, F.; Martínez, M.J.; Gutiérrez, A.; delRío, J.C. 2005. Biodegradation of lignocellulosics: microbial, chemical, and enzymatic aspects of the fungal attack of lignin. International Microbiology 8: 195-204.

Messner, K.; Fackler, K.; Lamaipis, P.; Gindl, W.; Srebotnik, E.; Watanabe, T. 2003. Overview of white-rot research: where we are Today. In: Goodell, B; Nicholas, DD; Schulz, T Pleurotus (Eds). Wood deterioration and preservation. Advances in our changing world. ACS Symp Series 845. Am Chem Soc, Washington, DC. p Pleurotus 73-96.

Mohammadi Goltapeh, E.; Pourjam, E. 2010. Principles of mushroom cultivation. $6^{\text {th }}$ edn. Tarbiat Modares University Press: Iran.

Morais, H.; Ramos, C.; Matos, N.; Forgács, E.; Cserháti, T.; Almeida, V.; Oliveira, J.; Darwish, Y.; Ille's, Z. 2002. Liquid chromatographic and electrophoretic characterization of extracellular b-glucosidase of Pleurotus ostreatus grow in organic waste. J Chromatogr B 770: 111-119.

Nikolouli, K.; A., Pournou, McConnachie, G., Tsiamis, G., Mossialos, D., 2016. Prokaryotic diversity in biodeteriorated wood coming from the Bükkábrány fossil forest. International Biodeterioration \& Biodegradation 108: 181-190.

Pettipher, G.L. 1987. Cultivation of the oyster mushroom (Pleurotus ostreatus) on lignocellulosic waste. Journal of the Science of Food and Agriculture 41: 259-265.

Rosado, F.R.; Carbonero, E.R.; Kemmelmeier, C.; Tischer, C.A.; Gorin, P.A.J.; Iacomini, M. 2002. A partially 3-O-methylated (1-4)-linked b-D-galactan and b-D-mannan from Pleurotus ostreatoroseus Sing. FEMS Microbiology Letters 212: 261-265.

Schmidt, O. 2006. Wood and Tree Fungi: Biology, Damage, Protection, and Use. Springer: Berlin Heidelberg.

Schmidt, O.; Gaiser, O.; Dujesiefken, D. 2012. Molecular identification of decay fungi in the wood of urban trees. European Journal of Forest Research 131: 885-891.

Schwarze, F.W.M.R.; Engels, J.; Matthek, C. 2004. Fungal strategies of wood decay in trees. $2^{\text {nd }}$ ed. Springer: Berlin Heidelberg New York.

Solomko, E.F.; Eliseeva, G.S. 1998. Biosynthesis of group B vitamins by the fungus Pleurotus ostreatus in submerged culture. Prikladnaya Biokhimiya 24: 64-169.

Stienen. T.; Schmidt, O.; Huckfeldt, T. 2014. Wood decay by indoor basidiomycetes at different moisture and temperature. Holzforschung 68: 9-15.

TAPPI standard. TAPPI. 1998. Standard methods for acid-insoluble lignin in wood and pulp, T 222. om-98.

TAPPI standard. TAPPI. 1997. Cellulose in wood, T 17 wd-97.

Viitanen, H.A. 1997. Modeling the time factor in the development of brown rot decay in pine and spruce sapwood. Holzforschung 51: 99-106. 